\title{
Sympathoadrenal Activity in Fasting Pregnant Rats
}

\author{
DISSOCIATION OF ADRENAL MEDULLARY AND \\ SYMPATHETIC NERVOUS SYSTEM RESPONSES
}

\author{
James B. Young and Lewis Landsberg, Department of Medicine and Thorndike \\ Laboratory, Harvard Medical School and Beth Israel Hospital, Boston, \\ Massachusetts 02115
}

A B S T RA C T The pattern of urinary catecholamine excretion in fasting differs in pregnant and nonpregnant rats, which suggests that the sympathoadrenal response to fasting is altered by pregnancy. In fasting nonpregnant animals, urinary norepinephrine (NE) excretion decreases and epinephrine $(\mathrm{E})$ excretion remains unchanged, whereas the excretion of both catecholamines rises significantly with refeeding. In contrast, fasting third-trimester pregnant rats exhibit a $420 \%$ increase in urinary $E$ and a $345 \%$ increase in urinary $\mathrm{NE}$, elevations which fall with refeeding. Specific evaluation of sympathoadrenal activity in fasting pregnant rats reveals stimulation of the adrenal medulla and suppression of sympathetic nerves. In fasting third-trimester rats the adrenal content of $\mathrm{E}$ is $37 \%$ lower in innervated adrenals as compared with contralateral denervated glands, which indicates the presence of neurally-mediated adrenal medullary activation. Adrenalectomy completely abolishes the fastinginduced rise in urinary $E$ and $N E$ in pregnant rats. Studies with 2-deoxy-D-glucose suggest that stimulation of the adrenal medulla results from hypoglycemia, which is present after $3 \mathrm{~d}$ of fasting in pregnant rats (plasma glucose $36.7 \mathrm{mg} / \mathrm{dl}$ ). Sympathetic nervous system activity, as measured by $\left[{ }^{3} \mathrm{H}\right] \mathrm{NE}$ turnover in the heart, decreases in fasting pregnant rats despite hypoglycemia, a response similar to that seen in fasting nonpregnant animals where plasma glucose is maintained above $50 \mathrm{mg} / \mathrm{dl}$. The calculated NE turnover rate is $44 \%$ lower in $2-\mathrm{d}$ fasted pregnant rats than in fed pregnant animals $(17.6 \pm 1.3$ vs. $31.3 \pm 1.8 \mathrm{ng} \mathrm{NE} /$ heart per $h$, respectively). Thus adrenal medullary and sympathetic nervous system responses in fasting pregnant rats appear to be dissociated, which suggests that

Dr. Young is the recipient of U. S. Public Health Service fellowship AM 05755.

Received for publication 6 December 1978 and in revised form 5 March 1979. diet-induced changes in sympathetic activity and stimulation of the adrenal medulla by hypoglycemia may be independently regulated.

\section{INTRODUCTION}

Studies from our laboratory with measurements of norepinephrine turnover have demonstrated decreased activity of the sympathetic nervous system in fasting nonpregnant rats (1). Urinary catecholamine excretion in fasting rats is reduced as well, thus supporting the concept of fasting-induced reduction in sympathetic activity (2). The pattern of urinary catecholamine excretion during fasting in third-trimester pregnant rats, however, is markedly different from that observed in nonpregnant animals. Previous studies have shown that pregnant rats excrete increased quantities of catecholamines during fasting, coincident with the development of hypoglycemia (3). The studies described in this report were designed to examine specifically the functional state of the adrenal medulla and of sympathetic nerves in fasting pregnant rats.

Adrenal medullary function was assessed by quantitating changes in epinephrine $(\mathrm{E})^{1}$ excretion and in adrenal $\mathrm{E}$ content, and sympathetic activity in the heart was estimated by measuring cardiac norepinephrine (NE) turnover. Whereas depletion of adrenal E clearly reflects a rate of $E$ secretion in excess of the rate of biosynthesis and thereby serves, when present, as a readily understandable index of adrenal medullary stimulation, measurement of $\mathrm{NE}$ turnover is a less wellappreciated means of assessing sympathetic activity. The $\left[{ }^{3} \mathrm{H}\right] \mathrm{NE}$ technique of $\mathrm{NE}$ turnover depends upon the amine transport system of the axonal membrane; after intravenous administration, $\left[{ }^{3} \mathrm{H}\right] \mathrm{NE}$ is rapidly cleared from the circulation by uptake into sympathetic

${ }^{1}$ Abbreviations used in this paper: 2-DG, 2-deoxy-D-glucose; $E$, epinephrine; NE, norepinephrine. 
nerve endings (4). After equilibration with the endogenous NE stores (within $5 \mathrm{~min}$ ) the tracer is released along with endogenous $\mathrm{NE}$ and becomes a valid marker of $\mathrm{NE}$ release (5). The rate of disappearance of the tracer, expressed as the rate of change of specific activity of $\mathrm{NE}$, is a monoexponential function of time which can be analyzed in quantitative terms: the slope $(k)$ represents the fractional NE turnover or percentage of decline per hour; the NE turnover rate can be calculated from the product of the fractional NE turnover $(k)$ and the endogenous NE content (pool size) of the particular organ (5). Because release of NE depends upon sympathetic nerve impulses, more rapid release, reflected in a faster turnover, indicates increased sympathetic activity; conversely, decreased turnover implies decreased sympathetic activity. Calculation of $\mathrm{NE}$ turnover allows statistical comparison of sympathetic activity in various organs in different situations.

The results reported in this paper indicate that although fasting rat pregnancy is associated with adrenal medullary stimulation secondary to hypoglycemia, the activity of cardiac sympathetic nerves is suppressed by fasting as it is in nonpregnant animals. The increase in urinary NE excretion observed during fasting in pregnant rats originates exclusively from the adrenal medulla. Thus, in pregnant rats, fasting selectively stimulates the adrenal medulla at a time when the activity of the sympathetic nervous system is reduced. This dissociation between the functional state of the adrenal medulla and the sympathetic nervous system in fasting pregnant rats implies that diet-induced changes in sympathetic activity are fundamentally different than the stimulation of the adrenal medulla that occurs in response to hypoglycemia.

\section{METHODS}

Virgin and timed-pregnant Sprague-Dawley rats were obtained from Charles River Breeding Laboratories (Wilmington, Mass.) and from Zivic-Miller Laboratories (Allison Park, Pa.). They were housed two per cage (or four per double cage) in a constant-temperature animal room $\left(20^{\circ} \mathrm{C}\right)$, except when placed in individual metabolic cages, and were allowed free access to water and Charles River Breeding Laboratories rat chow (R-M-H 3000; Agway Inc., Syracuse, N. Y.), except where noted. While fasting, the animals were permitted free access to a hypotonic electrolyte solution of $\mathrm{Na}^{+}(78 \mathrm{meq} / \mathrm{liter})$ and $\mathrm{K}^{+}(15 \mathrm{meq} / \mathrm{liter})$. In the metabolic-cage experiments animals were fed a synthetic no- $\mathrm{Na}^{+}$diet $(49.1 \%$ sucrose by weight, $30.1 \%$ casein, $10.0 \%$ lard, $5.0 \%$ corn oil, $2.0 \%$ vitamin dietfortification mixture $3.04 \%$ normal mineral mixture, and $0.75 \% \mathrm{KCl}$ ) and were given the hypotonic electrolyte solution to drink. All studies in pregnant animals were performed in the third week (third trimester) and were terminated on day 20 or 21 of gestation (with the day of mating designated as day zero).

Surgical procedures were performed by the supplier (ZivicMiller Laboratories). Unilateral splanchnic nerve section was done on day 10 of gestation in the pregnant animals, bilateral splanchnic nerve section on days 10 and 11 , and bilateral adrenalectomy on day 3 . Similar surgical procedures in virgin animals were performed on the same calendar days. After adrenalectomy, operated animals received corticosterone in oil $(1 \mathrm{mg} / \mathrm{kg})$ by subcutaneous injection daily; controls received daily injections of vehicle. The daily replacement dose of corticosterone was increased to $3 \mathrm{mg} / \mathrm{kg}$ immediately before metabolic-cage study and continued for the duration of the experiment. 2-Deoxy-D-glucose (Sigma Chemical Co., St. Louis, Mo.) was dissolved in isotonic saline and injected in a dose of $500 \mathrm{mg} / \mathrm{kg}$ i.p.

L- $\left[7,8-{ }^{3} \mathrm{H}(\mathrm{N})\right] \mathrm{NE}(30-40 \mathrm{Ci} / \mathrm{mmol}$ sp act; New England Nuclear, Boston, Mass.) was purified before use by column chromatography with alumina as described below. Before intravenous administration, the $\left[{ }^{3} \mathrm{H}\right] \mathrm{NE}$ was diluted to an appropriate concentration with isotonic saline. Tracer $\left[{ }^{3} \mathrm{H}\right] \mathrm{NE}$ was injected into the tail veins of unanesthetized animals in a total volume of $1.0 \mathrm{ml}$. The rats were killed at preselected times by cervical dislocation or decapitation. For each time point in the studies of NE turnover four to nine animals were killed from each experimental group, totalling 35-40 animals per experiment. The organs were rapidly removed, frozen on dry ice, and stored at $-20^{\circ} \mathrm{C}$ for later processing (usually within $2 \mathrm{wk}$ ). The tissues to be analyzed for NE (and for $\mathrm{E}$ where indicated) were homogenized in iced $0.4 \mathrm{~N}$ perchloric acid in a ground glass homogenizer (Duall-Kontes Glass Co., Vineland, N. J.) to extract the $\mathrm{NE}$ and precipitate the proteins. After volume adjustment, the precipitated protein was removed by low-speed centrifugation.

Isolation of $\mathrm{NE}$ (and $\mathrm{E}$ ) from the perchloric acid extract was by column chromatography with alumina as previously described (6). NE (and E) was absorbed onto the alumina column at $\mathrm{pH} 8.6$ and eluted with $0.2 \mathrm{~N}$ acetic acid. The alumina (Woelm neutral, ICN Nutritional Biochemicals, Cleveland, Ohio) had previously been purified according to the method of Anton and Sayre (7). Recovery of added NE or E was usually in excess of $90 \%$ with a variation between columns of $<10 \%$; the results were corrected for recovery as determined in each experiment. Assay of NE on the alumina eluate was by the fluorescent method of von Euler and Lishajko (8) and of NE and E by a modification of the spectrophotofluorometric method of Crout (9). Aliquots of the alumina eluates were counted for $\left[{ }^{3} \mathrm{H}\right] \mathrm{NE}$ by liquid scintillation spectrometry in a Nuclear-Chicago three channel scintillation counter (Nuclear-Chicago Corp., Des Plaines, Ill.) (6) Efficiency for ${ }^{3} \mathrm{H}$ in this system is 6-8\%.

Urine for $\mathrm{E}$ and $\mathrm{NE}$ determinations from animals in individual metabolic cages was collected under oil with the addition of $1.5 \mathrm{ml}$ of $2 \mathrm{~N} \mathrm{HCl}$ for each 24-h collection. After isolation on alumina columns as described above, urinary $\mathrm{E}$ and $\mathrm{NE}$ were measured spectrophotofluorometrically by a modification of the method of Crout (9). Plasma glucose was measured on blood obtained by decapitation with a glucose analyzer (model 23A, Yellow Springs Instrument Co., Inc., Yellow Springs, Ohio). Glycogen in liver was measured enzymatically (10), and DNA was measured by the method of Burton (11).

Data are presented as mean \pm SEM unless otherwise noted. Statistical analyses used the Student's $t$ test for unpaired variables, or for paired variables where appropriate. In the studies of NE turnover the data were plotted semilogarithmically. The slope of the decline in NE specific activity over time after $\left[{ }^{3} \mathrm{H}\right] \mathrm{NE}$ administration was calculated by the least squares method. The endogenous $\mathrm{NE}$ level remained constant over the course of the turnover experiments. NE turnover rates were calculated as the product of the fractional turnover rate and the endogenous NE concentration of a particular organ (5). $95 \%$ confidence intervals were determined for the $\mathrm{NE}$ turnover rates as previously described (12). Comparison of fractional turnover rates was made with the Student's $t$ test. 


\section{RESULTS}

Effect of fasting on plasma glucose and urinary catecholamine excretion in third-trimester pregnant rats. Plasma glucose levels during fasting are markedly lower in pregnant than in nonpregnant animals and man (13-15). In 24 pregnant rats, fasted for $3 \mathrm{~d}$, plasma glucose levels were $36.7 \pm 3.1 \mathrm{mg} / \mathrm{dl}$. After an additional day of fasting (Table I) plasma glucose levels were $35.9 \pm 3.3 \mathrm{mg} / \mathrm{dl}$ in pregnant rats as compared with $58.9 \pm 3.6 \mathrm{mg} / \mathrm{dl}$ in virgin fasted animals $(P<0.001)$. The pattern of urinary catecholamine excretion with fasting in pregnant rats also differs from that observed in nonpregnant animals. Previous studies from this laboratory (2) demonstrated that in nonpregnant rats, urinary $\mathrm{NE}$ excretion declined $18 \%$ below basal values over a 4-d fast whereas urinary $E$ was unchanged. With refeeding, both urinary $\mathrm{NE}$ and $\mathrm{E}$ rose to levels significantly higher than base line. The results of a similar study of fasting in third-trimester pregnant rats are presented in Fig. 1. In these animals, in contrast with nonpregnant rats, both urinary $\mathrm{NE}$ and $\mathrm{E}$ increased during fasting from $0.48 \pm 0.05$ to $2.12 \pm 0.29$ $\mu \mathrm{g} \mathrm{NE} /$ rat per $\mathrm{d}$ and from $0.20 \pm 0.04$ to $1.05 \pm 0.25 \mu \mathrm{g}$ $\mathrm{E} / \mathrm{rat}$ per $\mathrm{d}$ by the $3 \mathrm{rd} \mathrm{d}$, and then decreased toward base line with a single day of refeeding.

Changes in the renal clearance of catecholamines with fasting could conceivably contribute to the observed increase in urinary catecholamine excretion. Marked alterations in renal handling of catecholamines were, however, excluded by the following experiment. 18 pregnant rats (day 19) were placed in metabolic cages. One-half of the group was fed ad libitum for $2 \mathrm{~d}$,

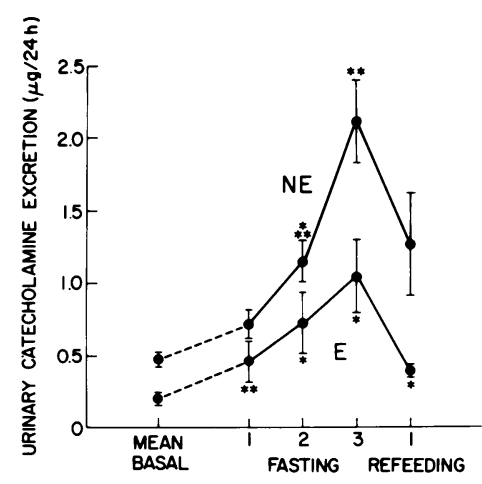

FIGURE 1 Effect of fasting and refeeding on urinary NE and $E$ excretion in third-trimester pregnant rats. Pregnant rats in individual metabolic cages were fed a synthetic no- $\mathrm{Na}^{+}$diet for a 3-d base-line period and during the single day of refeeding. Free access to a hypotonic electrolyte solution was provided throughout the experiment. Data are presented as mean $\pm S E M$ for daily urine catecholamine measurements from six animals. The mean basal value is the average $N E$ and $\mathrm{E}$ excretion for the $3 \mathrm{~d}$ of base-line collections. Comparisons are between individual fasting or refeeding days and the mean basal values. ${ }^{*} P<0.05,{ }^{* *} P<0.02$, and ${ }^{* * *} P<0.005$. and the other group fasted; both groups were allowed free access to hypotonic saline as described above. After $2 \mathrm{~d}$, an intravenous bolus of $\mathrm{L}-\left[{ }^{3} \mathrm{H}\right] \mathrm{NE}$ (200 $\mu \mathrm{Ci} / \mathrm{kg}$ ) was administered, and the urine was collected for $2 \mathrm{~h}$. L- $\left[{ }^{3} \mathrm{H}\right] \mathrm{NE}$ excretion during this period did not differ in fasted $(2,117 \pm 370 \mathrm{nCi})$ as compared with fed pregnant animals $(2,638 \pm 397 \mathrm{nCi})$. Creatinine excretion was also similar over this period $(0.55 \pm 0.07 \mathrm{mg}$ fasted vs. $0.62 \pm 0.05 \mathrm{mg}$ fed).

Thus, in pregnant rats the urinary catecholamine responses to fasting and refeeding are opposite to the pattern obtained in nonpregnant animals and reflect increased catecholamine secretion rather than alterations in renal clearance. The subsequent studies were undertaken to define the activity of the sympathetic nervous system and the adrenal medulla during fasting in rat pregnancy as well as to explore the connection between hypoglycemia and catecholamine stimulation.

Effect of fasting on the activity of the adrenal medulla in third-trimester pregnant rats. To examine specifically the effect of fasting during pregnancy on the activity of the adrenal medulla, adrenal $\mathrm{E}$ content was measured after $3 \mathrm{~d}$ of fasting in third-trimester pregnant rats (day 21 ). In fed pregnant animals, plasma glucose levels were $67.4 \pm 3.4 \mathrm{mg} / \mathrm{dl}$, and adrenal $\mathrm{E}$ content was $10.2 \pm 0.8 \mu \mathrm{g} / \mathrm{gland}$, whereas in the 3 - $\mathrm{d}$ fasted animals plasma glucose levels were $24.1 \pm 4.3 \mathrm{mg} / \mathrm{dl}$ and the adrenal glands contained only $7.6 \pm 0.9 \mu \mathrm{g} \mathrm{E} /$ gland, a decrease in adrenal $\mathrm{E}$ with fasting significant at the $P<0.05$ level. Thus, fasting in pregnancy is associated with both depletion of adrenal $\mathbf{E}$ and hypoglycemia, a finding consistent with the evidence of increased adrenal secretion obtained from measurements of urinary E excretion.

Because the adrenal medullary response to hypoglycemia is dependent upon intact neural connections (16), changes in the $\mathrm{E}$ content of innervated adrenals relative to denervated glands serve as an index of neurally mediated adrenal medullary stimulation. In Fig. 2 the effect of fasting on the adrenal content of $\mathrm{E}$ in innervated and denervated glands from virgin and pregnant rats is shown. Note that the $\mathrm{E}$ contained within the denervated glands did not differ among the various groups, measuring 14-17 $\mu \mathrm{g} / \mathrm{gland}$ in each group. No difference in adrenal $\mathrm{E}$ was observed in pairs of innervated and denervated glands from fed or fasted virgin rats. This suggests, in conjunction with previous studies of urinary $E$ excretion in fasting nonpregnant animals (2), that fasting for $4 \mathrm{~d}$ is not associated with demonstrable adrenal medullary stimulation. On the other hand, in pregnant rats, significant depletion of adrenal $\mathrm{E}$ from innervated glands occurred, consistent with neurally mediated stimulation of adrenal medullary secretion during fasting in these animals.

2-Deoxy-D-glucose (2-DG) is a glucose analogue known to stimulate the adrenal medulla, presumably 


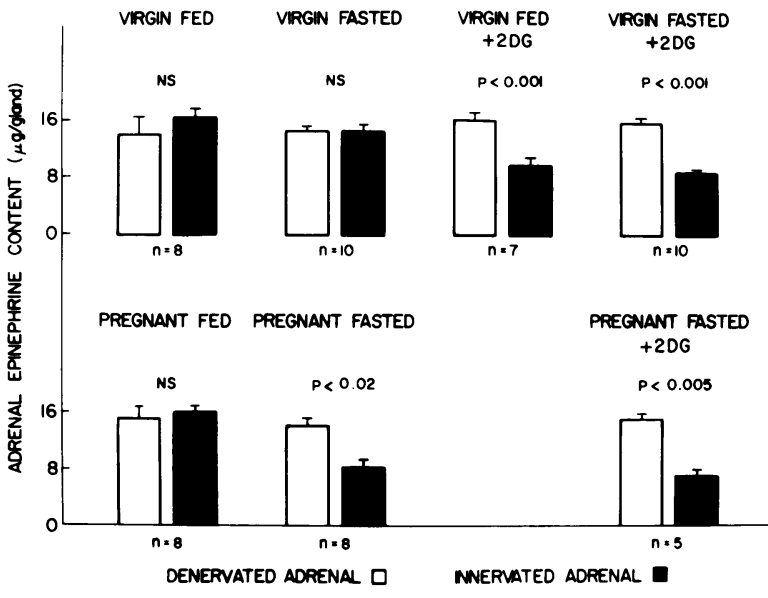

FigURE 2 Effect of fasting and 2-DG on adrenal epinephrine content in virgin and third-trimester pregnant rats. All animals underwent unilateral splanchnic nerve section $11 \mathrm{~d}$ before study. Fed and 4-d fasted animals received intraperitoneal injections of $2-\mathrm{DG}(500 \mathrm{mg} / \mathrm{kg})$ or saline $2 \mathrm{~h}$ before death. Data are presented as mean $\pm S E M$ for adrenal $E$ content in pairs of denervated (open bars) or innervated (closed bars) glands.

through inhibition of glucose metabolism in central neurons, a situation generally accepted as being similar to hypoglycemia $(17,18)$. To compare the effect of fasting in pregnancy with an acute glucopenic stimulus, 2-DG was administered to fed and fasted virgin rats and to fasted pregnant rats $2 \mathrm{~h}$ before removal of the adrenals (Fig. 2). In virgin fed and fasted animals, 2-DG induced an acute loss of $\mathrm{E}$ from the innervated adrenals, which demonstrates that neuroglucopenia in nonpregnant animals, either fed or fasted, causes comparable depletion of adrenal $E$ to that seen in fasting pregnant rats. In fasted pregnant rats, on the other hand, no additional depletion of adrenal $\mathrm{E}$ in the innervated glands was observed, which suggests that a maximal or near maximal adrenal medullary response had already been triggered.

The effect of 2-DG on plasma glucose in these animals is shown in Table I. In both fed and fasted virgin rats, 2-DG administration produced a marked increase in plasma glucose. The rise in plasma glucose after 2DG in fasted pregnant rats was much smaller. Although the lesser glucose response to 2-DG in fasted pregnant animals suggests that hypoglycemic stimulation of counterregulation in the fasted pregnant animals is already near maximum, significant differences in fuel homeostasis between pregnant and nonpregnant animals preclude a definitive statement of the extent of counterregulation based on blood glucose values alone. Furthermore, 2-DG is also detected by the glucose analyzer and consequently contributes to the observed increment in plasma glucose. Although the differential response in plasma glucose to $2-\mathrm{DG}$ in virgin and pregnant animals cannot be attributed entirely to a lack of specificity of the glucose measurement (Table I), possible differences in the volume of distribution of 2-DG in pregnant as compared with nonpregnant animals also confound the interpretation of counterregulatory events based only on the plasma glucose level.

Effect of fasting on sympathetic nervous system activity in third-trimester pregnant rats. Fasting in virgin rats has been shown to decrease the activity of sympathetic nerves in the heart, pancreas, and liver $(1,19)$. To investigate the possibility that, like the adrenal medulla, sympathetic nervous system responses to fasting differ between virgin and pregnant rats, direct measurement of sympathetic activity in the hearts of fasting pregnant rats was made with the NEturnover technique. The effect of fasting on cardiac NE turnover in pregnant rats is shown in Fig. 3. In this experiment fasting began $48 \mathrm{~h}$ before the injection of $\left[{ }^{3} \mathrm{H}\right] \mathrm{NE}$ and continued for the $24 \mathrm{~h}$ of the study. Halflife of disappearance of $\left[{ }^{3} \mathrm{H}\right] \mathrm{NE}$ increased during fasting from 9.5 to $22.8 \mathrm{~h}$. Fasting was associated with a highly significant reduction in fractional $\mathrm{NE}$ turnover $(k)$ from $7.28 \pm 0.14$ to $3.03 \pm 0.08 \% / \mathrm{h}(P<0.001)$ and in the calculated $\mathrm{NE}$ turnover rate from $31.3 \pm 1.8$ to $17.6 \pm 1.3 \mathrm{ng} \mathrm{NE} /$ heart per h (95\% confidence limits). Thus, fasting appears to reduce sympathetic activity in the heart in pregnant rats as it does in virgin animals.

To exclude the possibility that the increase in adrenal medullary catecholamine secretion might be responsible for the reduction in cardiac NE turnover in fasted pregnant rats, a similar experiment was performed in pregnant rats after bilateral splanchnic nerve section. In splanchnic-sectioned animals the adrenal medullary response to fasting is abolished by interruption of the

TABLE I

Effects of Fasting and 2-DG on Plasma Glucose in Virgin and Third-Trimester Pregnant Rats

\begin{tabular}{|c|c|c|}
\hline & \multicolumn{2}{|c|}{ Plasma glucose } \\
\hline & Virgin & Pregnant \\
\hline & \multicolumn{2}{|c|}{$m g / d l$} \\
\hline Fed & $113 \pm 3.8(8)$ & $86.9 \pm 4.1(8)^{*}$ \\
\hline + 2-DG & $254 \pm 8.9(6)$ & - \\
\hline Fasted (4-d) & $58.9 \pm 3.6(9)$ & $35.9 \pm 3.3(8)^{*}$ \\
\hline$+2-\mathrm{DG}$ & $265 \pm 4.9(10)$ & $50.1 \pm 7.1(4)^{*}$ \\
\hline
\end{tabular}

Virgin and third-trimester pregnant rats were fed ad libitum or fasted for $4 \mathrm{~d}$. On the day of study, 2-DG $(500 \mathrm{mg} / \mathrm{kg})$ was administered intraperitoneally, and the animals were killed $2 \mathrm{~h}$ later. Data are presented as mean \pm SEM. The numbers in parentheses represent the number of animals in each group. Glucose measured by the glucose analyzer also measures 2-DG. The addition of $50 \mathrm{mg} / \mathrm{dl}$ of 2-DG to a glucose solution of $100 \mathrm{mg} / \mathrm{dl}$ increases the resulting glucose measurement by $\cong 26 \mathrm{mg} / \mathrm{dl}$.

${ }^{*} P<0.001$, virgin vs. pregnant. 


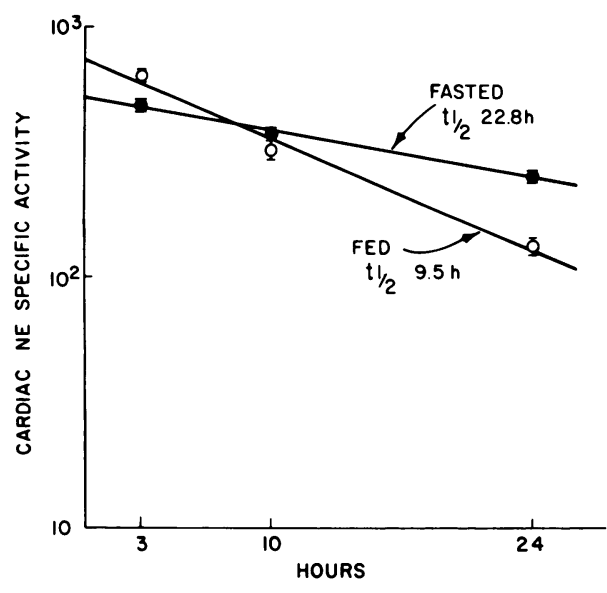

Figure 3 Effect of fasting on cardiac NE turnover in thirdtrimester pregnant rats. Fasted animals had been without food for $48 \mathrm{~h}$ before the injection of $\left[{ }^{3} \mathrm{H}\right] \mathrm{NE}(48 \mu \mathrm{Ci} / \mathrm{kg})$ and remained fasting for the duration of the experiment. Data are plotted as mean \pm SEM for specific activity of $\mathrm{NE}$ in hearts from five to six animals in each group at each time point. Open circles represent fed and closed circles represent fasted animals. Endogenous NE was constant over the course of the experiment with fasted and fed groups, but the level was significantly higher in the fasted animal (430 $\mathrm{ng} / \mathrm{heart}$ fed vs. $579 \mathrm{ng} /$ heart fasted, $P<0.001$ ). Some of this increase represents $E$ which was not specifically measured in this experiment. As noted in the text, the slope or fractional turnover rate and calculated $\mathrm{NE}$ turnover differed significantly in fed and fasted pregnant animals.

neural efferents to the adrenals. The results of this turnover experiment are illustrated in Fig. 4. As in the previous experiment, fasting began $48 \mathrm{~h}$ before the injection of tracer $\left[{ }^{3} \mathrm{H}\right] \mathrm{NE}$ and continued for the duration of the 24-h study. Fasting increased $t_{1 / 2}$ from 6.7 to $11.6 \mathrm{~h}$, decreased fractional NE turnover $(k)$ from $10.4 \pm 0.3$ to $5.79 \pm 0.17 \% / \mathrm{h}(P<0.01)$, and decreased the calculated $\mathrm{NE}$ turnover rate from $59.1 \pm 6.0$ to $39.0 \pm 2.8 \mathrm{ng} \mathrm{NE} /$ heart per $\mathrm{h}$ ( $95 \%$ confidence limits). An indication of the efficacy of the adrenal decentralization was provided by the lack of difference in adrenal $\mathrm{E}$ content between fed and fasted pregnant rats obtained at the completion of the turnover study and by the $27 \%$ depletion $(P<0.01$ compared with fasted operated animals) of adrenal $E$ in a similarly fasted intact group of pregnant animals.

Because circulating catecholamines contribute to the endogenous catecholamine stores in the heart by active transport into sympathetic nerve terminals, adrenal decentralization likewise obliterated the effect of adrenal medullary stimulation upon cardiac catecholamine content. In the animals from the 24-h time point in Fig. 4, cardiac NE and $\mathrm{E}$ content were the same in both fasted and fed groups $(0.553 \pm 0.062 \mu \mathrm{g}$ $\mathrm{NE}$ and $0.041 \pm 0.013 \mu \mathrm{g}$ E/heart in the fasted rats and $0.549 \pm 0.100 \mu \mathrm{g} \mathrm{NE}$ and $0.040 \pm 0.014 \mu \mathrm{g} \mathrm{E} /$ heart in the

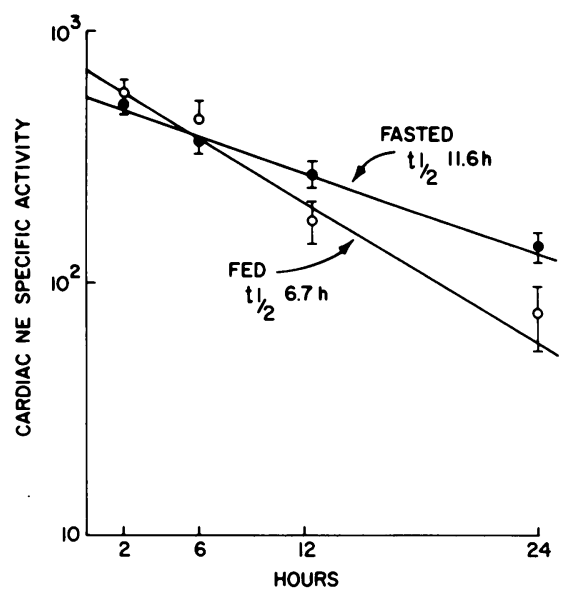

FIGURE 4 Effect of fasting on cardiac NE turnover in thirdtrimester pregnant rats after bilateral splanchnic nerve section. Bilateral splanchnic nerve section was performed 8-9 d before the start of the turnover study. Fasted animals had been without food for $48 \mathrm{~h}$ before the injection of $\left[{ }^{3} \mathrm{H}\right] \mathrm{NE}$ $(56 \mu \mathrm{Ci} / \mathrm{kg})$ and remained fasting for the duration of the experiment. Data are plotted as mean \pm SEM for specific activity of $\mathrm{NE}$ in hearts from four to nine animals in each group at each time point. Open circles represent fed and closed circles represent fasted animals. Fractional turnover and calculated NE turnover rate was significantly different in fed and fasted groups (see text). Bilateral splanchnic section appears to increase NE turnover (Fig. 3), perhaps by sequestering blood in the splanchnic circulation, but does not obscure the effect of fasting.

fed animals), whereas hearts from the simultaneously fasted group of intact rats contained $0.703 \pm 0.038 \mu \mathrm{g}$ NE (not significantly different from either operated group) and $0.111 \pm 0.010 \mu \mathrm{g} \mathrm{E} /$ heart $(P<0.005 \mathrm{vs}$. both operated groups). Thus fasting in pregnancy is associated with reduced sympathetic activity ( $\mathrm{NE}$ turnover) in heart, a decrease not secondary to adrenal medullary stimulation.

Effect of adrenalectomy or adrenal denervation during fasting in third-trimester pregnant rats. With evidence of increased adrenal medullary secretion and decreased sympathetic nervous system activity, the possibility that the adrenal medulla was also the source of the increased NE excreted in the urine during fasting was examined. In Fig. 5, urinary excretion of NE and $\mathrm{E}$ in adrenalectomized, corticosterone-replaced, and intact sham-injected pregnant rats is shown. Although in control animals, urinary $\mathrm{NE}$ excretion rose with fasting from $0.76 \pm 0.06 \mu \mathrm{g} \mathrm{NE} /$ rat per d during base-line collections to $1.89 \pm 0.26 \mu \mathrm{g} \mathrm{NE} / \mathrm{rat}$ per $\mathrm{d}$ $(P<0.01)$ by the 3 rd d of fasting and urinary E levels rose from $0.15 \pm 0.03$ to $1.02 \pm 0.14 \mu \mathrm{g} \mathrm{E} /$ rat per $\mathrm{d}(P$ $<0.001)$ over the same period, in adrenalectomized animals no change was observed with fasting in either urinary $\mathrm{NE}$ or $\mathrm{E}$ excretion. On the 3rd d of fasting, urinary $\mathrm{NE}$ excretion in adrenalectomized rats was sig- 


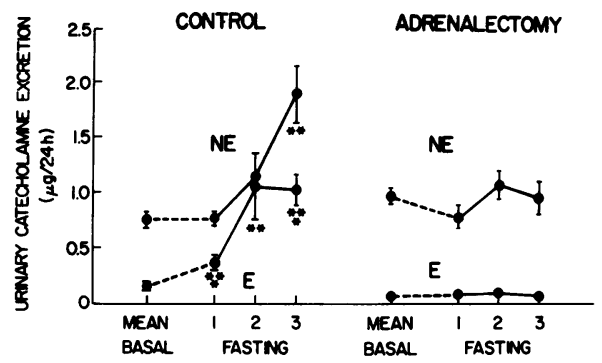

FIGURE 5 Effect of fasting on urinary $\mathrm{NE}$ and $\mathrm{E}$ excretion in intact and adrenalectomized, corticosterone-replaced, thirdtrimester pregnant rats. Adrenalectomy was performed $12 \mathrm{~d}$ before the start of urine collections. Daily subcutaneous injections of corticosterone in oil or of vehicle alone began the day after adrenalectomy and continued throughout the experiment. Rats were fed a synthetic no- $\mathrm{Na}^{+}$diet for the 3-d baseline period and were given free access to a hypotonic electrolyte solution during the period of urine collections. Data are presented as mean \pm SEM for daily urine catecholamine measurements from seven control and nine adrenalectomized animals. Mean basal value is the average $\mathrm{NE}$ and $\mathrm{E}$ excretion for the $3 \mathrm{~d}$ of base-line collections. Comparisons are between individual fasting days and the mean basal values. ${ }^{* *} P<0.02$ and ${ }^{* * *} P<0.001$.

nificantly less than in control animals $(0.97 \pm 0.14$ vs. $1.89 \pm 0.26 \mu \mathrm{g} \mathrm{NE} /$ rat per $\mathrm{d}, P<0.01)$. Thus the increases in $\mathrm{E}$ and $\mathrm{NE}$ excreted in the urine of fasted pregnant rats both derive from stimulation of the adrenal medulla.

The effect of withdrawal of the adrenal medullary contribution to counterregulation during fasting in pregnancy is indicated in Table II. Neither adrenalectomy nor bilateral splanchnic nerve section affected the plasma glucose concentration compared with control in fasting pregnant rats. A small, but statistically significant decrease in hepatic glycogen content remaining after $3 \mathrm{~d}$ of fasting in pregnant rats was observed in the animals with bilateral splanchnic nerve section. Because the difference was small and the operation also interrupted sympathetic outflow to the abdominal viscera, including liver, the physiologic importance of this observation is unclear.

\section{DISCUSSION}

As described previously $(13,14)$ and confirmed in this study, fasting produces greater plasma glucose lowering in pregnant rats than in virgin controls, and levels below $50 \mathrm{mg} / \mathrm{dl}$ are frequently observed. Although hypoglycemia is a recognized stimulant of the adrenal medulla (16), the effect of hypoglycemia on the activity of the sympathetic nervous system is less well defined. Although several studies (20-22) have reported modest elevations in plasma NE with hypoglycemia consistent with sympathetic stimulation, the source of the NE has never been determined. Experiments in animals with analysis of adrenal venous effluent have demonstrated increased concentrations of both $\mathrm{E}$ and $\mathrm{NE}$ in the adrenal venous blood after hypoglycemia (23-26), thus raising the possibility that the adrenal gland is responsible for the increase in circulating NE. This study demonstrates conclusively that the increased urinary excretion of $\mathrm{NE}$ in fasting pregnant rats originates from the adrenal medulla and suggests that increased plasma NE levels in man during hypoglycemia may also derive, at least in part, from the adrenal gland.

TABLE II

Effect of Adrenal Denervation and Adrenalectomy on Plasma Glucose and Hepatic Glycogen in Fed and Fasted Third-Trimester Pregnant Rats

\begin{tabular}{lcc}
\hline & Plasma glucose & Hepatic glycogen \\
\hline A $\quad$ mg/dl & $m g / m g$ DNA-P \\
$\quad \begin{array}{l}\text { Fasted 3-d intact (9) } \\
\text { Fasted 3-d bilateral splanchnic } \\
\quad \text { section (9) }\end{array}$ & $39.4 \pm 3.8$ & $8.0 \pm 2.0$ \\
$\begin{array}{l}\text { Fed, bilateral splanchnic section } \\
\quad(5)\end{array}$ & $45.7 \pm 5.0$ & $2.0 \pm 0.9^{*}$ \\
$\quad$ B $\quad 87.0 \pm 2.6$ & $335 \pm 48$ \\
$\quad$ Fasted 3-d intact (7) \\
Fasted 3-d adrenalectomized (9)
\end{tabular}

Protocol as described in Fig. 5 for (A) and as in Fig. 6 for (B). The fed and 3-dfasted operated animals in (A) comprised the 24-h time point in Fig. 5; the 3-d-fasted intact rats were studied concurrently. Data are presented as mean \pm SEM. The numbers in parentheses represent the number of animals in each group.

${ }^{*} P<0.02$ as compared with fasted intact. 
This study also demonstrates that sympathetic activity in the heart is diminished by fasting in pregnant rats (Fig. 3) as it is in nonpregnant animals (1). Because pregnant rats with bilateral splanchnic section also demonstrate reduced cardiac $\mathrm{NE}$ turnover rate with fasting (Fig. 4), the decrease in cardiac NE turnover shown here cannot be attributed to alterations in the $\left[{ }^{3} \mathrm{H}\right] \mathrm{NE}$-turnover technique by increased catecholamines of adrenal medullary origin. Although only cardiac NE turnover was measured in this study, suppression of $\mathrm{NE}$ turnover in the pancreas and the liver has been demonstrated to occur with fasting in nonpregnant animals (19). It seems likely that the suppression of cardiac-sympathetic activity demonstrated here reflects generalized suppression of the sympathetic nervous system, but at this time the possibility that sympathetic activity is not suppressed by fasting in certain areas critical to metabolic regulation cannot be excluded. Other studies of nerve impulse traffic from implanted microelectrodes that demonstrate no evidence of sympathetic nerve stimulation after 2-DG administration at a time when a marked increase in adrenal nerve impulse traffic occurs (27) support a dissociation between sympathetic nervous system and adrenal medullary responses. Such a dissociation suggests that hypoglycemic stimulation of the adrenal medulla and diet-induced changes in sympathetic activity may represent fundamentally different processes.

A dissociation in adrenal medullary and sympathetic nervous system responses has implications for the signal(s) to the central nervous system that couple changes in sympathetic activity with changes in diet. At this time the mechanism(s) that coordinate central sympathetic activity with dietary intake is unknown, but presumably it accounts for both stimulation of sympathetic activity with overfeeding (28) and suppression with fasting (1). Although numerous factors may be involved in the dietary regulation of sympathetic activity, circulating glucose and(or) insulin probably play an important role. The demonstration, in this study, of sympathetic suppression during fasting in pregnant rats despite concomitant hypoglycemia sufficient to recruit adrenal medullary secretion, indicates either that plasma glucose concentration is not directly involved in control of sympathetic activity, or that the maximum suppressive effect of decreased plasma glucose levels in fasting occurs after the marginal reduction in the plasma glucose level observed during a brief fast in nonpregnant animals. Although the latter situation is possible, it seems unlikely. Moreover, the plasma glucose level does not provide a satisfactory explanation for sympathetic stimulation by overfeeding. Insulin, on the other hand, would appear to be an ideal signal for coordinating sympathetic activity with caloric intake. The concentration of insulin in plasma, in contrast with that of glucose, varies widely over the course of the day and provides an integrated assessment of caloric intake. Furthermore, because insulin is the major signal to tissues outside the central nervous system that calories have been assimilated, it would be both parsimonious and logical for insulin to serve that function for the brain as well. Appropriate studies to examine directly the influence of insulin on sympathetic outflow are lacking, but a report demonstrating increased plasma $\mathrm{NE}$ levels in diabetics in response to insulin (without hypoglycemia) is consistent with this hypothesis (29).

The contribution of catecholamines to metabolic regulation in fasting pregnant rats is not entirely clear. The adrenal medulla is apparently not essential for the maintenance of the plasma glucose level itself because the removal of adrenal catecholamines by adrenalectomy or denervation is not associated with any further lowering of the plasma glucose level in fasting pregnant rats (Table II). As metabolic substrates are continually recycled between peripheral tissues and the liver, however, static measurements of plasma glucose may fail to detect important effects of adrenal catecholamines in the metabolic adaptation to fasting. Kusaka and Ui (30), on the basis of kinetic analysis of E-induced activation of the Cori cycle, have suggested that the importance of $\mathrm{E}$ lies in the maintenance of the circulating glucose pool without a concomitant increase in glucose utilization. Increased adrenal $\mathrm{E}$ secretion during fasting in pregnant animals may thus contribute to the maintenance of the circulating glucose pool, possibly by stimulation of gluconeogenesis from muscle via the Cori cycle.

\section{ACKNOWLEDGMENTS}

The excellent technical assistance of M. Berardino, S. Gunn, M. Scanlon, N. Langhans, and K. Allen, and the secretarial assistance of Mrs. Edith Cusher are gratefully acknowledged.

This study was supported in part by U. S. Public Health Service grants AM 20378 and RR76.

\section{REFERENCES}

1. Young, J. B., and L. Landsberg. 1977. Suppression of the sympathetic nervous system during fasting. Science (Wash. D. C.). 196: 1473-1475.

2. Landsberg, L., and J. B. Young. 1978. Fasting, feeding and regulation of the sympathetic nervous system. New Engl. J. Med. 298: 1295-1301.

3. Herrera, E., R. H. Knopp, and N. Freinkel. 1969. Urinary excretion of epinephrine and norepinephrine during fasting in late pregnancy in the rat. Endocrinology. 84: $447-450$.

4. Whitby, L. G., J. Axelrod, and H. Weil-Malherbe. 1961. The fate of $\mathrm{H}^{3}$-norepinephrine in animals. J. Pharmacol. Exp. Ther. 132: 193-201.

5. Neff, N. H., T. N. Tozer, W. Hammer, E. Costa, and B. B. Brodie. 1968. Application of steady-state kinetics to the uptake and decline of $\mathrm{H}^{3}-\mathrm{NE}$ in the rat heart.J. Pharmacol. Exp. Ther. 160: 48-52.

6. Landsberg, L., M. B. Berardino, and P. Silva. 1975. 
Metabolism of ${ }^{3} \mathrm{H}-\mathrm{L}-\mathrm{dop}$ a by the rat gut in vivo: evidence for glucuronide conjugation. Biochem. Pharmacol. 24: $1167-1176$.

7. Anton, A. H., and D. F. Sayre. 1962. Study of the factors affecting the aluminum oxide-trihydroxyindole procedure for the analysis of catecholamines. J. Pharmacol Exp. Ther. 138: 360-375.

8. von Euler, U. S., and F. Lishajko. 1961. Improved technique for the fluorimetric estimation of catecholamines. Acta Physiol. Scand. 51: 348-355.

9. Crout, J. R. 1961. Catecholamines in urine. In Standard Methods of Clinical Chemistry. D. Seligson, editor. Academic Press, Inc., New York. 3: 62-80.

10. Keppler, D., and K. Decker. 1974. Glycogen. Determination with amyloglucosidase. In Methods of Enzymatic Analysis. H. U. Bergmeyer, editor. Academic Press, Inc., New York. 2nd English edition. 3: 1127-1131.

11. Burton, K. 1956. A study of the conditions and mechanisms of the diphenylamine reaction for the colorimetric estimation of deoxyribonucleic acid. Biochem. J. 62: 315-323.

12. Taubin, H. L., B. Djahanguiri, and L. Landsberg. 1972. Noradrenaline concentration and turnover in different regions of the gastrointestinal tract of the rat: an approach to the evaluation of sympathetic activity in the gut. Gut. 13: $790-795$.

13. Scow, R. O., S. S. Chernick, and M. S. Brinley. 1964. Hyperlipemia and ketosis in the pregnant rat. Am. J. Physiol. 206: 796-804.

14. Herrera, E., R. H. Knopp, and N. Freinkel. 1969. Carbohydrate metabolism in pregnancy. VI. Plasma fuels, insulin, liver composition, gluconeogenesis, and nitrogen metabolism during late gestation in the fed and fasted rat. J. Clin. Invest. 48: 2260-2272.

15. Felig, P., and V. Lynch. 1970. Starvation in human pregnancy: hypoglycemia, hypoinsulinemia, and hyperketonemia. Science (Wash. D. C.). 170: 990-992.

16. Young, J. B., and L. Landsberg. 1977. Catecholamines and intermediary metabolism.J. Clin. Endocrinol. Metab. 6: $599-631$.

17. Brown, J. 1962. Effects of 2-deoxyglucose on carbohydrate metabolism: review of the literature and studies in the rat. Metab. Clin. Exp. 11: 1098-1112.

18. Wegienka, L. C., S. G. Grasso, and P. H. Forsham. 1966. Estimation of adrenomedullary reserve by infusion of 2-deoxy-D-glucose. J. Clin. Endocrinol Metab. 26: $37-45$.

19. Young, J. B., and L. Landsberg. 1979. Effect of diet and cold exposure on norepinephrine turnover in pancreas and liver. Am. J. Physiol. 236: E524-E533.

20. Christensen, N. J. 1974. Plasma norepinephrine and epinephrine in untreated diabetics, during fasting and after insulin administration. Diabetes. 23: 1-8.

21. Christensen, N. J., K. G. M. M. Alberti, and O. Brandsborg. 1975. Plasma catecholamines and blood substrate concentrations: studies in insulin induced hypoglycaemia and after adrenaline infusions. Eur. J. Clin. Invest. 5: 415-423.

22. Garber, A. J., P. E. Cryer, J. V. Santiago, M. W. Haymond, A. S. Pagliara, and D. M. Kipnis. 1976. The role of adrenergic mechanisms in the substrate and hormonal response to insulin-induced hypoglycemia in man. J. Clin. Invest. 58: 7-15.

23. Goldfien, A., S. Zieleli, R. H. Despointes, and J. E. Bethune. 1958. The effect of hypoglycemia on the adrenal secretion of epinephrine and norepinephrine in the dog. Endocrinology. 62: 749-757.

24. Silver, M. 1960. The output of adrenaline and noradrenaline from the adrenal medulla of the calf. J. Physiol. (Lond.). 152: 14-29.

25. Crone, C. 1965. The secretion of adrenal medullary hormones during hypoglycemia in intact, decerebrate and spinal sheep. Acta Physiol. Scand. 63: 213-224.

26. Bloom, S. R., A. V. Edwards, R. N. Hardy, K. W. Malinowska, and M. Silver. 1975. Endocrine responses to insulin hypoglycaemia in the young calf. J. Physiol. (Lond.). 244: 783-803.

27. Niijima, A. 1975. The effect of 2-deoxy-D-glucose and D-glucose on the efferent discharge rate of sympathetic nerves. J. Physiol. (Lond.). 251: 231-243.

28. Young, J. B., and L. Landsberg. 1977. Stimulation of the sympathetic nervous system during sucrose feeding. $\mathrm{Na}$ ture (Lond.). 269: 615-617.

29. Gundersen, H. J. G., and N. J. Christensen. 1971. Intravenous insulin causing loss of intravascular water and albumin and increased adrenergic nervous activity in diabetes. Diabetes. 26: 551-557.

30. Kusaka, M., and M. Ui. 1977. Activation of the Cori cycle by epinephrine. Am. J. Physiol. 232: E145-E155. 